IRA-International Journal of Education \& Multidisciplinary Studies

ISSN 2455-2526; Vol.04, Issue 02 (2016)

Pg. no. 346-354

Institute of Research Advances

http://research-advances.org/index.php/IJEMS

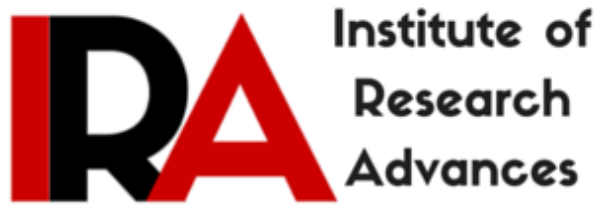

\title{
The professional bodies and associations that should know an Information Scientist: An Analytical Study
}

\author{
P.K. Paul ${ }^{1}$, A. Bhuimali ${ }^{2}$, K. Kumar ${ }^{3}$ \& B. Karn $^{4}$ \\ ${ }^{1}$ FBAS, Indian Institute of Engineering Science and Technology (IIEST), Shibpur- An \\ Institute of National Importance, Howrah, West Bengal, India. \\ ${ }^{2}$ Vice Chancellor, Raiganj University, Raiganj, West Bengal, India. \\ ${ }^{3}$ Vice Chancellor, VMS University, Gangtok, Sikkim, India. \\ ${ }^{4}$ Associate Dean (SW), Birla Institute of Technology, Mesra, Ranchi, India.
}

Type of Review: Peer Reviewed

DOI: http://dx.doi.org/10.21013/jems.v4.n2.p12

\section{How to cite this paper:}

Paul, P., Bhuimali, A., Kumar, K., \& Karn, B. (2016). The professional bodies and associations that should know an Information Scientist: An Analytical Study. IRA International Journal of Education and Multidisciplinary Studies (ISSN 2455-2526), 4(2), 346-354. doi:http://dx.doi.org/10.21013/jems.v4.n2.p12

(C) Institute of Research Advances

\section{(cc) EY-NC}

This work is licensed under a Creative Commons Attribution-Non Commercial 4.0 International License subject to proper citation to the publication source of the work.

Disclaimer: The scholarly papers as reviewed and published by the Institute of Research Advances (IRA) are the views and opinions of their respective authors and are not the views or opinions of the IRA. The IRA disclaims of any harm or loss caused due to the published content to any party. 


\begin{abstract}
Information Scientist is one of the novel profession which is responsible for building information infrastructure and proper information transfer cycle by promotion of information activities. The information activities are includes the collection, selection, organization, processing, management and dissemination. Information Scientist need to know the basic of information and similar knowledge facets and also several tools and technologies for managing information and technologies. There are many associations and institutions working closely with the Information Science and allied subjects. And as an Information Scientist, it is important and urgent that they should know about these organizations for better and healthy fulfillment of their aims and objectives.
\end{abstract}

\title{
Keywords-
}

Information, Information Scientist, Information Science, Technology Management, Information Transfer Cycle, Knowledge Management, Information Society

\section{Introduction-}

Information Scientist is an interdisciplinary person who is responsible for information and also technology solutions for better and healthy information transparencies and information transfer cycle. Information Scientist is mainly needed for managing information, managing technologies, and more importantly connections between the information and users. They are many way dedicated to the solid information development and side by side societal development (See Fig: 1) Hence they need to know about the psychology of the users for better and more utilizations of the information. Hence information behavior and user study is important and valuable task of the Information Scientist [01], [11]. There are many foundations have been established in the area of internet if Information Scientist. The nature of Information Scientist is related with the information and technology and thus it is important that Information Scientist should be aware about these organizations and institutions for better activity and job performance [02], [05], [12]. There are many other Information Scientist allied professionals (please see Fig: 2) who may need to oversee regarding such associations, organizations etc [02],[03], [12]. The international organizations and associations and their activities and functions need to follow-up by the Information Scientist as much as possible [07],[08], [13].

\section{Objectives and Agenda-}

The main aim and objective of this research paper is includes but not limited to the following aspects-

- To know about the basic of the Information Scientist and their need.

- To learn about the main aims and objectives of Information Scientist.

- To know about the future potentials of Information Scientist by knowing the associations and functions.

- To learn about the associations, foundations and organizations which are related with the aim and objectives of the Information Scientist.

- To know about the functions and activities of these organizations and to introduce and use such gained knowledge in the working sectors. 


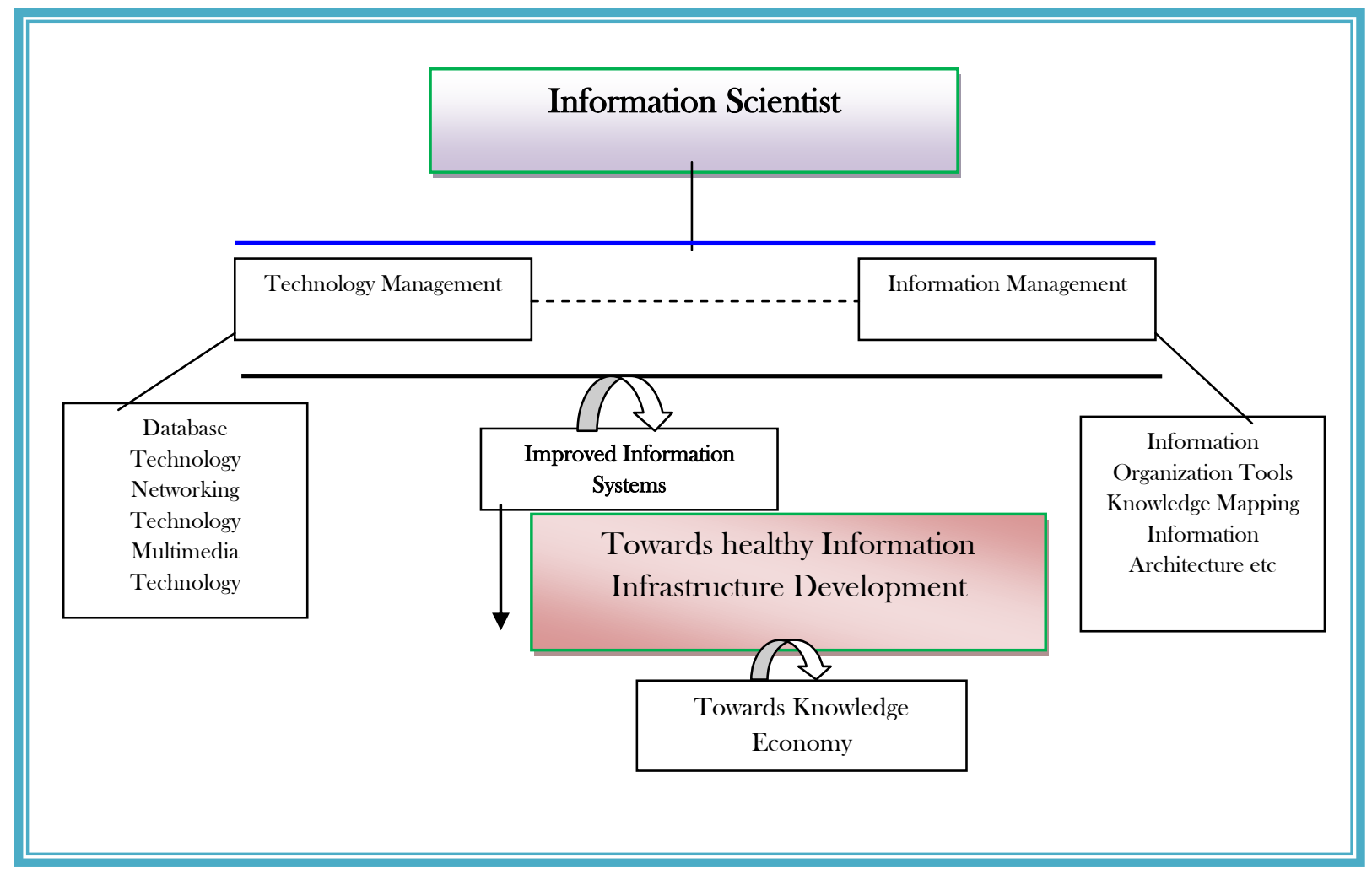

Fig: 1-Depicted the Information Scientist and allied Professionals role for solid Development of Society powered by Technologies

\section{Methodologies-}

This research paper is a kind of conceptual one and also deal the role and features of a policy paper. And thus secondary sources have used to know more about the Information Scientist and their professions. Hence several universities and institutes; their websites has been handled. Similarly to know information of the possible organizations and associations and websites of the concerned companies have been analyzed and reviewed.

\section{International Associations that should know an Information Scientist-}

Preparation and building of advance information infrastructure for the health information transfer cycle of the organization are the key task of Information Scientist. Information scientists previously deemed only as the key mover of the information foundations whereas today the need of each and every type of organizations desires the position for proper information collection, selection, organization and management [04], [06], [13]. Moreover an information scientist today provides the right information and to right person any time by using computing methods and allied technologies [09], [10], [13]. Information Scientist is need to take care about the techno-managerial issues and it is valuable that an Information Scientist should know about the related foundations and societies who are in touch of information, technology and managerial aspects. A brief on these associations, foundations and organizations etc have been provided as follows (also refer Fig: 3). 


\section{The Association for Information Science and Technology (ASIS\&T)—}

The domain of Information Science \& Technology has redefined by the ASIS\&T i.e. Association for Information Science and Technology which renamed from the American Society for Information Science. This is a nonprofit making organization and dedicated for the development of domain of Information Science and Technology and other related fields [20], [21]. This is partially responsible for the development of information governance and culture and removing the information divide. So betterment in digital divide is the main agenda of the ASIS\&T. the ASIS\&T was established 80 years back with the nomenclature of American Documentation Institute (ADI) in the 1937. Initially the organization was responsible for the digitalization of microfilm and explains its role as a vehicle and obviously for the information dissemination. Initially the ASIS\&T was mainly dedicated to the information science and its promotion including the subjects, professionalism, scientific advancement and so on. There is a limitation on information management tools in the 1970's and thereafter and in this regard ASIS\&T played a great role solid development and promotion. During the 1970's the development of Computing and Information Technology changes the whole concept of Information Science practice which include the collection, selection, organization, processing and management and mostly with several means. The ASIS\&T is today engaged in several domains and such are-

- Engineering.

- Linguistics.

- Librarianship.

- Computer Science.

- Physical Science.

- Communication.

- Chemistry and Chemical Science.

- Education Science and so on.

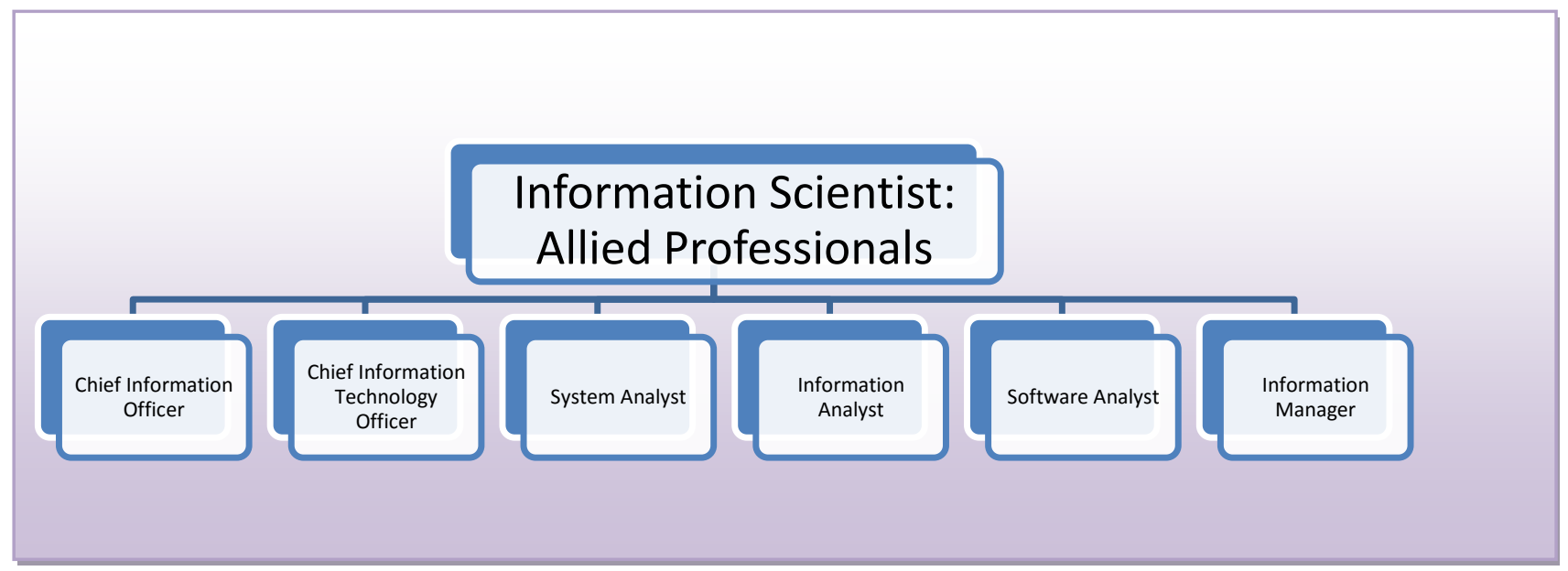

Fig: 2-The Information Scientist allied professionals at a glance

There was a need and strategy of ASIS\&T to become a society which should have a common interest of improvement of the society by designing and building storing, retrieving, analyzing, managing and archiving and mainly the dissemination of information. ASIS\&T regularly conducts the seminar, conferences and knowledge sessions for updating IST skills. They also publish two important research publications- 
- Journal of Association for the Information Science and Technology (JASIST).

- Bulletin for the Information Science and Technology [20], [21].

The organization also provide the membership to the interested members working in the information and technology fields and broadly in the areas mentioned above.

Finally the ASIS\&T is responsible for the political, social, personal and economic development with the help of information and content [19].

\section{Association for Information Systems (AIS) -}

Association for Information Systems (AIS) is the important information systems based professional organization and popular around the world [26], [27]. The Association for Information Systems has an international characteristic and responsible for the promotion of the information systems and allied domain and mainly by the practitioners of the fields. The stakeholders of this organization is includes but not limited to the experts, researchers, professor, practitioners in Information Systems, Information Sciences, Information Technology \& Computing, Electronics, Informatics, Management Information Systems - and so on. Presently the Association for Information Systems consisted with members from over 90 countries and these are mainly managed by these three regional hubs [26], [27]-

- The American Regional Sector.

- The Europe and African Regional Sector.

- The Asia Pacific Centers.

The Association for Information Systems is purely engaged in the study and practice area of the information systems by providing the membership, offering knowledge sessions such as seminars, conferences etc. Importantly the Association for Information Systems is also responsible for the publishing journals and conference proceedings etc, training programs etc. The Association for Information Systems mainly popular for their two renowned international conferences namely International Conference on Information Systems (ICIS), American Conference for Information Systems, Pacific Asia Conference on Information Systems and so on. Some of the popular research publications of the AIS are include-

- Journal of the Association for Information Systems.

- Communication of Association for Information Systems.

- Association for Information Systems Transaction on HCI.

- AIS Transaction on Replication Research.

- Journal of Information Technology Theory and Applications. Etc 
This way the Association for Information Systems is actively engaged with its chapters and systems and solid and responsible governing bodies. Business and Information Systems Engineering become an important part of the AIS in today's context.

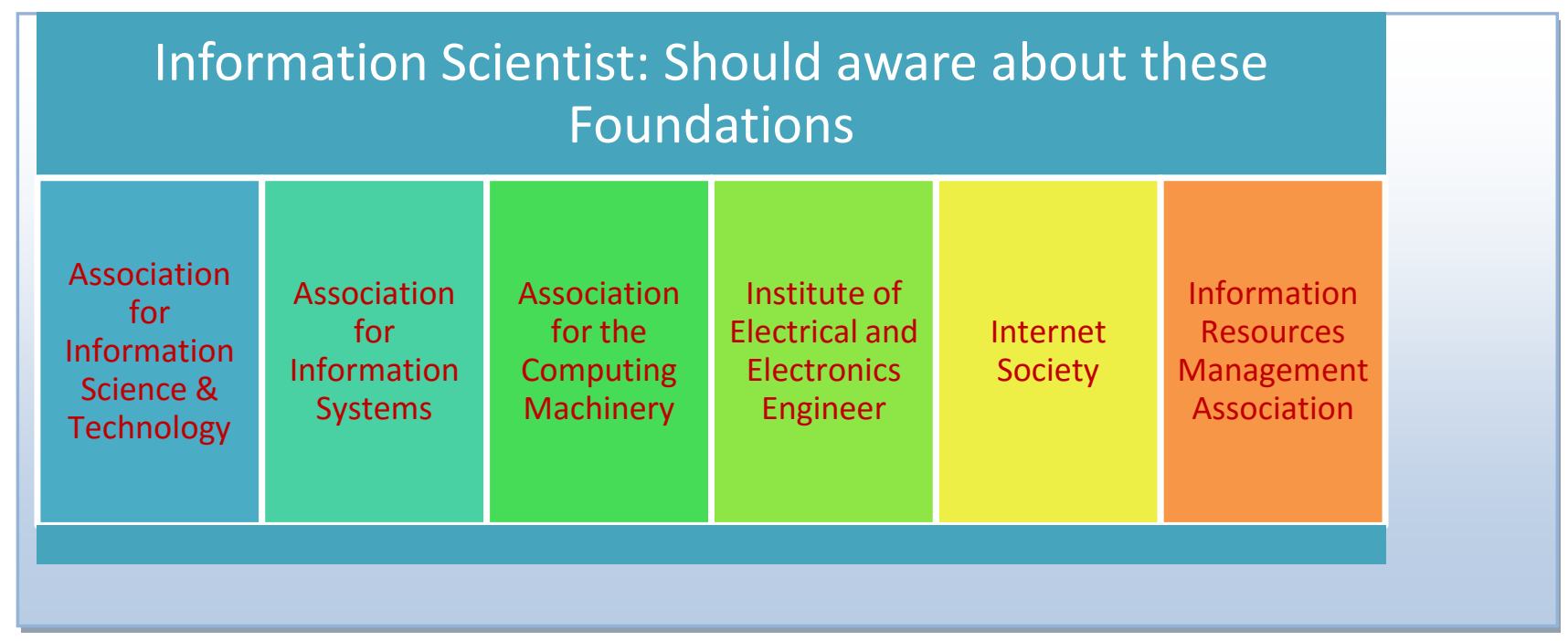

Fig: 3- The important foundations and associations need to take care by the Information Scientist

Ultimately the AIS is dedicated to the preparation of information systems in a leading education hub in the globe. Interacting man-information-machine is also a valuable agenda of the Association for Information Systems in many contexts [26], [27].

\section{Association for the Computing Machinery (ACM)—}

The Association for the Computing Machinery (ACM) is an international most popular and biggest society in the field of computing and allied sciences. It was founded in 1974 as nonprofit making venture for promoting computing and information technology domains. Its headquarter is located in the New Year City. The agenda of IEEE Computer Society is many ways matches with the Association for the Computing Machinery. The ACM is published many research work as Journals, Conference Proceedings etc. They are involved several other knowledge and academic event as well [24], [25]. The annual event of the Association for the Computing Machinery catches thousands of the practicing and theoretical aspects of computing and Information Technology. The Association for the Computing Machinery is ultimate responsible for the following activities such as-

- To develop and promote the core activities of the ACM i.e. the preparing and building the organization with true international spirit.

- To provide the latest ideas, communication with the output to the people who are interested in the IT and Computing.

- To spreading the knowledge by conducting the seminars, conferences in the core and allied domain of the Information Systems.

- Promoting new technologies and systems for better and healthy sustainable world.

- Promoting and development of the education, training and research in the areas of Information Systems and Technology, Computing and Technology, Knowledge Management and Engineering etc [24], [25].

Finally the keep the collaboration and communication among the distinguished scientist, distinguished engineers, distinguished researcher in the area of Information Systems and so on. The award and 
appreciation to the professionals and organizations are also important activities of the Association for the Computing Machinery. The Information Scientist may took and engaged the Association for the Computing Machinery's organizational benefits etc.

\section{Institute of Electrical and Electronics Engineers (IEEE)—}

The Institute of Electrical and Electronics Engineers (IEEE) is actually a professional association and foundation and has it's headquarter recognized office in the New York. The IEEE is established in 1963 and earlier known as the American Institute of Electrical Engineers and also as Institute of Radio Engineers [22], [23]. Popularly The Institute of Electrical and Electronics Engineers known as IEEE (pronounced as I Triple E). The Core aim of the IEEE is providing the IEEE standards, Conferences, and also publications. In the The Institute of Electrical and Electronics Engineers professionals have engaged from the wide range of areas such as Computer Scientist, Software Engineers, Software Developer, Information Technology Professionals, Physician, Pharmacist and also technical organizations. Earlier the The Institute of Electrical and Electronics Engineers was mainly engaged in the areas of Electronics and Communication Engineering but today the organization also involved in some other work and assignments such as power electronics, health technologies, bio medical engineering, Information and Communication Technology, Cyber Security, Transportation, Computing with Nano-Technology. The Institute of Electrical and Electronics Engineers (IEEE) is working with following units-

- Biometrics Council.

- Nano Technology Council.

- System Council.

- Sensors Council.

- Council of RFID.

- Superconductor Council etc.

Managing and organizing the knowledge session and events are the main agenda of the Institute of Electrical and Electronics Engineers in many contexts. The IEEE Digital Library is the main name in this context [22], [23].

Thus Information Scientist need to aware about these organizations and foundations for solid and successful fulfillment of the aim and agendas and building healthy information infrastructure in the organizations, academic institutions and research units [13], [15], [16]. Moreover the Information Scientist also need take oversee other related national foundations too [14], [17], [18].

\section{Findings-}

- Information Scientist is an interdisciplinary professional which deals with the information and technology.

- Information Scientist profession is mainly used in the universities and companies for managing information, decision making.

- Associations and foundations from the area of interest of Information Scientist have a great impact on professional improvement and empowerment.

- There is a misconception on Information Scientist position in different segments.

\section{Suggestions-}

- Know more about the technologies and latest computing etc for better information technology solutions.

- Information Scientist need to aware about the psychological areas and matters and thus they need to touch with the cognitive science. 
- Information Scientist need to get membership and other affiliations means for better and healthy organizations practice and improved job and activities.

\section{Conclusions-}

Information Scientist is information and technological positions need the management principles requirement. There are many associations and foundations in the computing, information and technology based domains and Information Scientist need to take care about these organizations for better utilization and fulfillment of complete aim and agenda fulfillment. Information Scientist is responsible for information delivery directly and indirectly and thus they are also responsible for removing the information divide in many contexts. Moreover the digital divide may help in improvement of the digital divide and building a complete information infrastructure building with proper balancing of the other gradients.

\section{References-}

[1] Abeysekera, I. and Guthrie, J. (2004) "How is intellectual capital being reported in a developing nation?", in Research in Accounting in Emerging Economies, Supplement 2: Accounting and Accountability in emerging and transition economies, Page 149-169.

[2] Agarwarl, Suren, (1989) "Development of Documentation in India: Social Science Information", New Delhi, India: Concept Pub. Co. Page 331.

[3] Buckland, Michael K and Liu (1995) "History of Information Science" in Annual Review of Information Science and Technology, 30, 385-416.

[4] C. Wang, Q. Wang, K. Ren, and W. Lou, (2010) "Privacy-Preserving Public Auditing for Data Storage Security in Cloud Computing, Proceedings of IEEE-INFOCOM, March, 1-9.

[5] Garfield, E. (1985). Essays of an Information Scientist, Vol: 8, p. 444-459, 1985 Current Contents,\# 47, p. 3-18, November 25, 1985. Current Contents,47, 3-18.

[6] Garfield, E. (2001). Recollections of Irving H. Sher 1924-1996: polymath/information scientist extraordinaire. Journal of the American Society for Information Science and Technology, 52(14), 1197-1202.

[7] Davenport, L., \& Cronin, B. (1989). What does hypertext offer the information scientist?. Journal of information science, 15(6), 369-372.

[8] Marco, G (1996) "Two false dogmas of Information Science" in New Library World, 97(11), 11-14.

[9] Mangla PB (2003) "Information Society, Information Systems And National Development: A Conceptual Approach.” In Annals of Library and Information Studies 50(2), 91-98.

[10] Nithya Sankar and Dr. S.S. Rau, (2011) "Managing Emotions to Managing Human Capital", International Journal of Management (IJM), 2 (2), 176 - 181.

[11] Paul, P. K. (2012). Information Scientist: Roles and Values with special Reference to their Appropriate Academic Programme and its availability in India. International Journal of Information Dissemination and Technology, 2(4), 245.

[12] Paul, P. K., Rajesh, R., Chaterjee, D., \& Ghose, M. K. (2013). Information scientist: Technological and managerial skill requirement in 21st century: An overview. Information Studies, 19(1), 29.

[13] Paul, P. K., (2013a) "Information Science and Technology [IST] and its comparision with Information Technology and Social Computing" in Abhinav National Journal of Science and Technology, 2 (3), 17-25.

[14] R. Bianchini and R.Rajamony (2004) "Power and energy management for server systems" in IEEE Computer, 37 (2), 68-74. 
[15] R.Sharmila and Dr.A.Subramani (2013) "Impact of Business Intelligence Tools in Executive Information Systems", in International Journal of Computer Engineering and Technology (IJCET), 4(1), 1-7.

[16] Renouf, A. (1993). What the linguist has to say to the information scientist.Journal of Document and Text Management, 1(2), 173-190.

[17] Tague, J., \& Carroll, J. (1973). Opinion Paper. Information in an Informationless World or The Making of an Information Scientist. Journal of the American society for information science, 24(1), 40-44.

[18] Vickery, Brian C (1994) "Fifty Years of Information Progress: A Journal of Documentation Review" London, England: in ASLIB;. Page-243.

[19] W. Boyd Rayward, (1997), "The Origin of Information Science and the International Institute of Bibliography/ International Federation for Information and Documentation", in Journal of the American Society for Information Science, 48(4), 289-300.

[20] https://www.asist.org/

[21] https://en.wikipedia.org/wiki/Association_for_Information_Science_and_Technology

[22] https://www.ieee.org/index.html

[23] https://en.wikipedia.org/wiki/Institute_of_Electrical_and_Electronics_Engineers

[24] http://www.acm.org/

[25] https://en.wikipedia.org/wiki/Association_for_Computing_Machinery

[26] http://aisnet.org/

[27] https://en.wikipedia.org/wiki/Association_for_Information_Systems 